\title{
Using phosphoproteomics data to understand cellular signaling: a comprehensive guide to bioinformatics resources
}

\author{
Sara R. Savage ${ }^{1,2}$ and Bing Zhang ${ }^{2,3^{*}}$
}

\begin{abstract}
Mass spectrometry-based phosphoproteomics is becoming an essential methodology for the study of global cellular signaling. Numerous bioinformatics resources are available to facilitate the translation of phosphopeptide identification and quantification results into novel biological and clinical insights, a critical step in phosphoproteomics data analysis. These resources include knowledge bases of kinases and phosphatases, phosphorylation sites, kinase inhibitors, and sequence variants affecting kinase function, and bioinformatics tools that can predict phosphorylation sites in addition to the kinase that phosphorylates them, infer kinase activity, and predict the effect of mutations on kinase signaling. However, these resources exist in silos and it is challenging to select among multiple resources with similar functions. Therefore, we put together a comprehensive collection of resources related to phosphoproteomics data interpretation, compared the use of tools with similar functions, and assessed the usability from the standpoint of typical biologists or clinicians. Overall, tools could be improved by standardization of enzyme names, flexibility of data input and output format, consistent maintenance, and detailed manuals.
\end{abstract}

Keywords: Phosphoproteomics, Bioinformatics tools, Kinase, Phosphorylation, Signaling

\section{Background}

Kinase signaling, the reversible enzymatic addition of a phosphate group to a substrate, is an essential part of cellular activity. Because its dysregulation contributes to many diseases, numerous clinical trials have been performed with kinase inhibitors resulting in over 50 FDAapproved small molecules and targeted antibodies [1, 2]. Therefore, detailed knowledge of the kinase signaling process is essential for the understanding of diseases and the development of new therapies.

*Correspondence: bing.zhang@bcm.edu

${ }^{2}$ Lester and Sue Smith Breast Center, Baylor College of Medicine, Houston, TX, USA

Full list of author information is available at the end of the article
While kinase signaling has been studied for over 100 years using a variety of experimental methods, the recent generation of mass spectrometry-based phosphoproteomic profiling allows for an unprecedented global exploration of phosphorylation. Phosphoproteomics data analysis involves two major steps. The first step includes the identification, phosphosite localization, and quantification of phosphopeptides. The second step aims to translate phosphopeptide identification and quantification results into novel biological and clinical insights. Although analyses in the first step are typically performed by the proteomics cores using standardized computational tools, those in the second step require and can benefit from active involvement of biologists and clinicians.

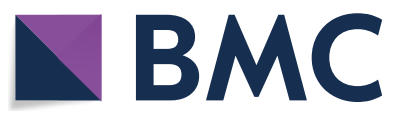

(c) The Author(s) 2020. This article is licensed under a Creative Commons Attribution 4.0 International License, which permits use, sharing, adaptation, distribution and reproduction in any medium or format, as long as you give appropriate credit to the original author(s) and the source, provide a link to the Creative Commons licence, and indicate if changes were made. The images or other third party material in this article are included in the article's Creative Commons licence, unless indicated otherwise in a credit line to the material. If material is not included in the article's Creative Commons licence and your intended use is not permitted by statutory regulation or exceeds the permitted use, you will need to obtain permission directly from the copyright holder. To view a copy of this licence, visit http://creativeco mmons.org/licenses/by/4.0/. The Creative Commons Public Domain Dedication waiver (http://creativecommons.org/publicdomain/ zero/1.0/) applies to the data made available in this article, unless otherwise stated in a credit line to the data. 
A vast array of resources and tools are available to facilitate the interpretation of phosphopeptide identification and quantification results. However, each of these tools exists as a silo without connection to tools with complementary functions. In addition, many tools have overlapping functions but differ in underlying knowledge bases, algorithms, input and output format of data, accessibility, advantages, limitations, and maintenance. Although newly developed tools are usually compared to similar, previously published tools, comparisons often do not include real-world, biological use-cases. For example, inference of kinase activity based on the observed phosphorylation of its substrates is a powerful application of phosphoproteomics profiling, and multiple methods have been developed to address this need [3, 4]. However, there has been little validation of the methods and only one benchmarking study comparing a few of the methods has been published [3].

Biological and clinical scientists are in the best position to extract biologically and clinically relevant findings from phosphoproteomics data, however, they are rarely consulted for tool design input or requested to test the final product. Furthermore, there is no comprehensive list of tools to aid those using phosphoproteomic data in their research. Therefore, this article aims to provide a comprehensive collection of resources that can be used to gain insights from phosphoproteomic data, including knowledge bases of kinases and phosphatases, phosphorylation sites, kinase inhibitors, and sequence variants affecting kinase function, and bioinformatics tools that can predict phosphorylation sites in addition to the kinase that phosphorylates them, infer kinase activity, and predict the effect of mutations on kinase signaling. We perform some benchmarking comparisons to determine the best tool available and assess usability of the tools from the standpoint of typical biologists or clinicians.

\section{Main text \\ Collection of knowledge bases and tools}

The OMICtools resource (https://omictools.com) is a manually curated collection of bioinformatics tools [5]. This site was searched in July 2019 for tools using the words 'kinase', 'phosphorylation', 'phospho', or 'phosphatase.' In addition, several more tools were collected from the literature. Only tools that were freely available, still accessible, and non-obsolete were included, and tools specific for organisms other than human were discarded. The year of last update was assumed to be the year of publication unless otherwise noted on the website. These tools may be accessed by a downloadable, locally-run tool (Tool) or by a website (Web) that may have downloadable (DL) results or database information. The website
URLs for all resources can be found in Additional file 1: Table S1. Each website was accessed in July 2019 and data statistics were collected for human proteins from downloadable files where possible and from websites or manuscripts for online-only resources.

\section{Knowledge bases of kinases and phosphatases}

General information about the components involved in kinase signaling is required throughout the analysis and interpretation of phosphoproteomics data. Knowledge bases for kinase signaling can be separated into those collecting information on the enzymes, and those collecting experimentally validated phosphorylation sites. Of the 16 different resources that collect information specifically on protein kinases and phosphatases, 13 provide data on kinases, while 5 provide data on phosphatases (Table 1). Only two resources, the Eukaryotic Protein Kinase \& Protein Phosphatase Database (EKPD) and its updated version $\mathrm{iEKPD}$ contain information on both types of enzymes [6]. Most databases are only available as online websites, but some provide an option for downloading data (Table 1).

The kinase knowledge bases can be further separated into two different types: those that include comprehensive data on all known protein kinases, and those that were developed for a specific purpose, such as collecting driver mutations in kinases (Kin-Driver). Notably, no kinase resource collects data on non-protein kinases. KinBase, which was developed by Gerard Manning, contains 538 protein kinases and is considered the primary source of human protein kinases and their classification [7]. Many other resources base their kinase list on KinBase.

Kinomer and KinG are general kinase sequence databases that provide very little other information $[8,9]$. KinMutBase, a collection of disease-causing mutations in protein kinase domains, is outdated, contains data on only 31 kinases, and primarily consists of broken links [10]. KinWeb and EKPD provide gene and protein identifiers, classification, description, and sequence information, but these data can also be found in other resources. However, KinWeb does have prediction of the disulfide bonding state of cysteines in the protein, as well as prediction of alpha helices, and EKPD presents data in an easy-to-read format $[6,11]$.

Use of the remaining general resources depends on which data one wants to access. KinaseNET, ProKinO, and iEKPD contain the most comprehensive data on protein kinases, but KinaseNET and ProKinO are only available as online resources [12, 13]. They include protein sequences, links to the kinases in other databases (e.g., UniProt, Ensembl, Entrez), information on the kinase domains, expression in tissue, and disease associations. 
Table 1 Knowledge bases of human kinases and phosphatases

\begin{tabular}{|c|c|c|c|c|c|c|}
\hline Name & Last update & Method of access & Version & Enzyme & $\begin{array}{l}\text { Human enzyme } \\
\text { number }\end{array}$ & References \\
\hline KinWeb & 2005 & Web & & Protein Kinases & 519 & [11] \\
\hline Kinomer & 2008 & Web|DL & 1 & Protein Kinases & 505 & {$[8]$} \\
\hline MOKCa & 2008 & Web & & Protein Kinases & 423 & [14] \\
\hline HuPho & 2012 & Web|DL & & Phosphatases & 313 & [18] \\
\hline KIDFamMap & 2012 & Web & & Protein Kinases & 399 & {$[17]$} \\
\hline EKPD & 2013 & Web & 1.1 & Protein Kinases and Phosphatases & 676 & {$[6]$} \\
\hline KinBase & 2014 & Web & & Protein Kinases & 538 & {$[7]$} \\
\hline KinMutBase & 2015 & Web|DL & 4 & Protein Kinases & 31 & [10] \\
\hline DEPOD & 2016 & Web|DL & 1.1 & Phosphatases & 239 & [19] \\
\hline KinaseNET & 2017 & Web & & Protein Kinases & $>530$ & \\
\hline Kin-Driver & 2017 & Web|DL & 82 & Protein Kinases & 518 & {$[15]$} \\
\hline Phosphatome & 2017 & Web & 3 & Phosphatases & 189 & {$[20]$} \\
\hline iEKPD & 2018 & Web|DL & 2.0 & Protein kinases and Phosphatases & 695 & {$[105]$} \\
\hline KLIFS & 2018 & Web|DL & 2.4 & Protein Kinases & 292 & {$[16,106]$} \\
\hline KinG & 2019 & Web|DL & & Protein Kinases & 1502 & [9] \\
\hline ProKinO & 2019 & Web & 2 & Protein Kinases & 538 & {$[12]$} \\
\hline
\end{tabular}

ProKinO specifically contains pathway information, mutations and their disease associations, chromosomal location of the kinase, and links to published manuscripts. KinaseNET includes PTMs, known binding partners, inhibitors, upstream kinases, downstream substrates, and information about regulation. KinaseNET provides all data on a single page, ProKinO requires more than 10 clicks on separate tabs and pages to obtain all information on a kinase, and iEKPD contains links for 13 additional annotations.

For disease studies, MOKCa and Kin-Driver specifically have data on protein kinase mutations [14, 15]. MOKCa has tissue specificity of mutations while KinDriver focuses on driver mutations and reports whether the mutation is activating or inactivating. KLIFS provides structural information for approximately half of the protein kinases bound to various ligands [16]. Finally, KIDFamMap combines structural data with known kinase inhibitors and diseases [17].

Because phosphatases are less well studied than kinases, there are fewer resources dedicated to their collection. EKPD and iEKPD provide the same information for phosphatases as they do for kinases. HuPho, however, was the first comprehensive collection of phosphatases and the database includes pathway and substrate data, as well as siRNA phenotype data and links to orthologs in other species [18]. DEPOD used data from HuPho as a starting point and therefore contains much of the same information [19]. Finally, Phosphatome.Net is the phosphatase version of KinBase [20]. The website contains basic classification and sequence information.

\section{Knowledge bases of phosphorylation sites}

Besides information about specific kinases and phosphatases, data on phosphorylation sites are important for studying the signaling process. Phosphorylation site databases collect information on the location of phosphorylated residues in proteins from experimental data. These experiments can be low-throughput or high-throughput. High-throughput phosphorylation site identifications are assigned by probability unlike the more stringent experimental validation in low-throughput experiments, but some databases combine sites from both types of experiments without identifying the source experiment type.

In addition to phosphorylation site information, 16 of the $27(60 \%)$ resources collect interactions between kinases or phosphatases and their substrates (Table 2). These often do not include the exact phosphorylation site, but instead provide interactions between an enzyme and its substrate at the gene level.

The four main resources for phosphorylation sites curated data manually from the literature (Fig. 1). HPRD and Swiss-Prot are general databases of all proteins [21, 22]. The remaining two, PhosphoSitePlus and Phospho. ELM, specifically contain phosphorylation site information [23, 24]. Both PhosphoSitePlus and Swiss-Prot are frequently updated, while HPRD and Phospho.ELM were last updated in 2010. All four of these databases also include kinase information for sites if known.

Other smaller databases were generated through manual curation or publication of a laboratory's own phosphorylation site data. KANPHOS collects phosphorylation sites in neural signaling identified by 
Table 2 Databases of phosphorylation sites

\begin{tabular}{|c|c|c|c|c|c|c|c|c|c|}
\hline Name & Last update & Method of access & Version & Sites & Proteins & Kinases & Phosphatases & Data Type & References \\
\hline PhosphoPep & 2007 & Web|DL & 2.0 & 3980 & & & & MS & {$[30,31]$} \\
\hline HPRD & 2010 & Web|DL & 9 & 78,005 & 11,807 & 291 & 42 & UNSP & {$[21,107,108]$} \\
\hline Phospho.ELM & 2010 & Web|DL & 9.0 & 26,651 & 5374 & 250 & & $\mathrm{HT}, \mathrm{LT}$ & {$[24,109,110]$} \\
\hline Phospho3D & 2010 & Web|DL & 2.0 & 1770 & & 59 & & $\mathrm{HT}, \mathrm{LT}$ & {$[44]$} \\
\hline PHOSIDA & 2011 & Web|DL & 3.24 & 24,262 & 8283 & & & MS & {$[26,111]$} \\
\hline HuPho & 2012 & Web|DL & & 190 & 121 & & 55 & UNSP & {$[18]$} \\
\hline PTMfunc & 2012 & Web & & 31,165 & & & & MS & {$[32]$} \\
\hline ANIA & 2013 & Web|DL & & 305 & 220 & & & $\mathrm{LT}$ & {$[35,112]$} \\
\hline PhosphoNetworks & 2013 & Web|DL & & & 1140 & 255 & & UNSP & {$[36]$} \\
\hline RegPhos & 2013 & Web|DL & 2.0 & 66,301 & 10,849 & 380 & & UNSP & {$[42,113]$} \\
\hline Kinome NetworkX & 2014 & $\mathrm{DL}$ & & 173,460 & 18,610 & 357 & & UNSP & {$[41]$} \\
\hline ProteomeScout & 2014 & Web|DL & 2 & 290,007 & 23,387 & & & MS & {$[39,114]$} \\
\hline LymPHOS & 2015 & Web|DL & 2 & 15,566 & 4937 & & & MS & {$[27,115]$} \\
\hline PhosphoDB & 2015 & Web & & 25,864 & 6222 & & & MS & [29] \\
\hline dbPAF & 2016 & Web|DL & 1.0 & 244,034 & 18,773 & & & UNSP & [38] \\
\hline DEPOD & 2016 & Web|DL & 1.1 & 253 & 210 & & 88 & UNSP & [19] \\
\hline KANPHOS & 2016 & Web & $\beta$ & & & 73 & & MS & [25] \\
\hline PhosphoAtlas & 2016 & $\mathrm{DL}$ & & 2595 & 1284 & 501 & & UNSP & {$[1]$} \\
\hline Phosphopedia & 2016 & Web & 1.0 & 109,611 & 11,428 & & & MS & [28] \\
\hline Phosphatome & 2017 & Web & 3 & 6008 & 2000 & 319 & 106 & UNSP & [20] \\
\hline PhosphoNET & 2017 & Web & & $966,817^{a}$ & 22,698 & 488 & & UNSP + pred & [43] \\
\hline PTMD & 2018 & Web|DL & 1.0 & 690 & 434 & & & UNSP & {$[37]$} \\
\hline qPhos & 2018 & Web|DL & & 199,071 & 18,402 & & & MS & [33] \\
\hline dbPTM & 2019 & Web|DL & V2019 & 257,527 & 19,713 & 25 & & UNSP & {$[40,64,116,117]$} \\
\hline PhosphoSitePlus & 2019 & Web|DL & Aug-19 & 239,664 & 20,115 & 372 & & $\mathrm{HT}, \mathrm{LT}$ & {$[23]$} \\
\hline Signor & 2019 & Web|DL & May-19 & 3593 & 1285 & 336 & 70 & UNSP & {$[34,118]$} \\
\hline Swiss-Prot & 2019 & Web|DL & Jun-19 & 40,135 & 7965 & 352 & & UNSP & {$[22,119]$} \\
\hline
\end{tabular}

The number of unique kinases and phosphatases reported to phosphorylate sites in the database is included. For some databases, these numbers include enzyme groups in addition to individual enzymes. Data type indicates whether the data are from mass spectrometry (MS) experiments, separated high-throughput (HT) and low-throughput (LT) experiments, or whether the database combines data from both HT and LT experiments without specifying (UNSP)

a Indicates inclusion of predicted phosphorylation sites (pred)

high-throughput experiments [25]. LymPHOS, PhosphoDB, Phosphopedia, and PHOSIDA are collections of data that were primarily produced in cell lines [26-29]. PhosphoPEP integrates mass spectrometry experiments from Cell Signaling Technology and their own laboratory [30, 31]. PTMfunc and qPhos both collect mass spectrometry experiments and add functional predictions and kinase activity from various tools [32, 33]. Signor extracts high quality signaling interactions from the literature [34]. Finally, ANIA, PTMD, and PhosphoNetworks curate the literature for a specific purpose. ANIA collects phosphorylation sites that serve as binding sites for 14-3-3 proteins, while PhosphoNetworks creates a kinase-substrate network curated from the literature and a protein microarray experiment, and PTMD collects disease-related phosphorylation sites [35-37].

The remaining resources integrate phosphorylation sites and kinase information from other databases
(Fig. 1). The database dbPAF collects phosphorylation sites from several databases [38]. ProteomeScout also collects phosphorylation sites from other databases along with literature-curated experiments and provides a tool for analyzing a user's data [39]. The database dbPTM collects all PTMs and the responsible enzyme from several sources [40]. Kinome NetworkX, RegPhos, and PhosphoAtlas curate and integrate data specifically to create kinase-substrate networks $[1,41,42]$. PhosphoNET is an online-only tool that includes predicted phosphorylation sites in addition to those with experimental evidence [43]. Finally, Phospho3D specifically collects phosphorylation sites with 3D structures [44].

Five databases collect information on phosphatasesubstrate interactions. As mentioned, DEPOD, HuPho, and Phosphatome.Net all curate enzyme interactions from the literature. HPRD and Signor also collect some site-specific phosphatase information. 


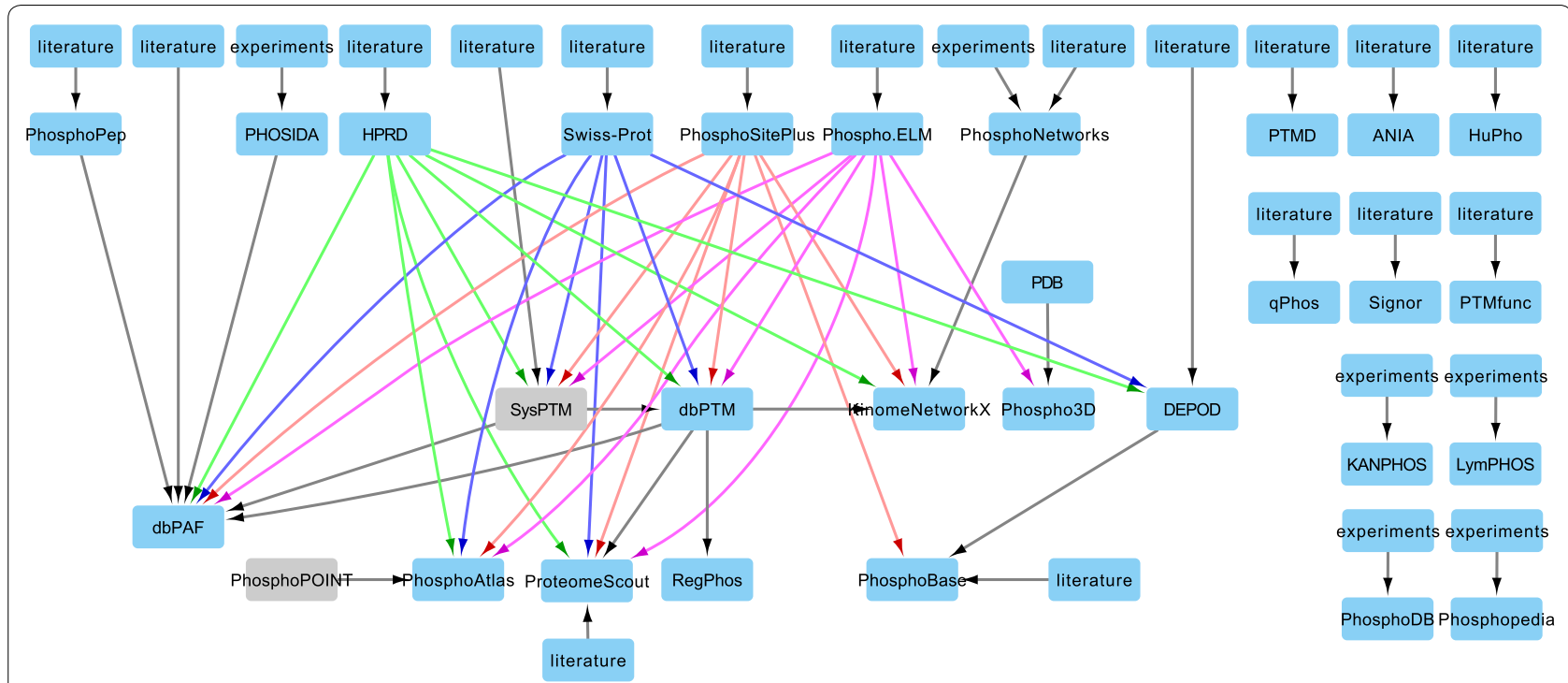

Fig. 1 Network of phosphorylation site and kinase-substrate interaction databases. Gray nodes indicate databases that are no longer accessible. Arrows point from the knowledge source to the collecting database. Arrows originating from the four most highly used databases are colored by source (green $=$ HPRD, blue $=$ Swiss-Prot, red $=$ PhosphoSitePlus, pink $=$ Phospho.ELM)

Each database contains a different number of phosphorylation sites and enzyme-substrate relationships depending on the source and method of collection (Table 2). ProteomeScout, PhosphoSitePlus, dbPTM, and dbPAF contain the most experimentally validated, downloadable sites. The site numbers for these four databases include specific protein isoforms, as do several other resources. PhosphoAtlas contains substrates for the largest number of individual kinases. Signor, SwissProt, RegPhos, Phospho3D, dbPTM, and Phospho.ELM have substrates for individual kinases and kinase families. Finally, PhosphoSitePlus has substrates for some specific kinase isoforms.

\section{Errors in substrate databases}

Based on our examination, PhosphoSitePlus is the preferred resource for experimentally-identified phosphorylation sites and kinases for phosphorylation sites. PhosphoSitePlus is frequently updated, well-curated, and distinguishes between low and high-throughput identified sites. The downstream integrating databases suffer from ID mapping errors. For example, in PhosphoAtlas there is an entry for PEG (paternally expressed gene 3) phosphorylating CDC25B. PEG is not a known kinase, but pEg3 kinase (also known as maternal embryonic leucine zipper kinase, $M E L K)$ is known to phosphorylate CDC25B [45]. Many of the downstream databases also have issues with PDPK1 and PDK1. The gene PDPK1, 3 -phosphoinositide-dependent protein kinase 1, produces a protein known to the biological community as
PDK1. However, there is an additional kinase, pyruvate dehydrogenase kinase, that is produced by the gene $P D K 1$. Databases that try to integrate sites frequently attribute the substrates of $P D P K 1$ to $P D K 1$. Finally, integrating databases propagate errors from the original databases. For example, HPRD contains an entry for PTPN11 phosphorylating PTK2B although PTPN11 is a known phosphatase and not a kinase. The original manuscript connected to this entry confirmed that PTPN11 is a phosphatase and that it just binds to PTK2B at that particular site [46]. Databases that collect information from HPRD, such as RegPhos and PhosphoAtlas, include this incorrect entry for PTPN11.

\section{Known substrates of kinases and phosphatases}

The four main databases of kinases together produce 485 substrate sets of individual kinases and kinase families (Fig. 2a). PhosphoSitePlus contains the most unique sites, while other databases contribute only a few additional sites per kinase. CSNK2A1 has the most substrates (596), while over half of the sets contain fewer than 10 substrates.

For substrates of phosphatases, DEPOD, HPRD, and Phosphatome.Net combined produce sets for 83 phosphatases. The most unique information comes from DEPOD and Phosphatome.Net. The number of known sites for each phosphatase is far fewer than that for kinases. PPP2CA has the most substrates (167), while $70 \%$ of the phosphatases have fewer than 10 substrates (Fig. 2b). 


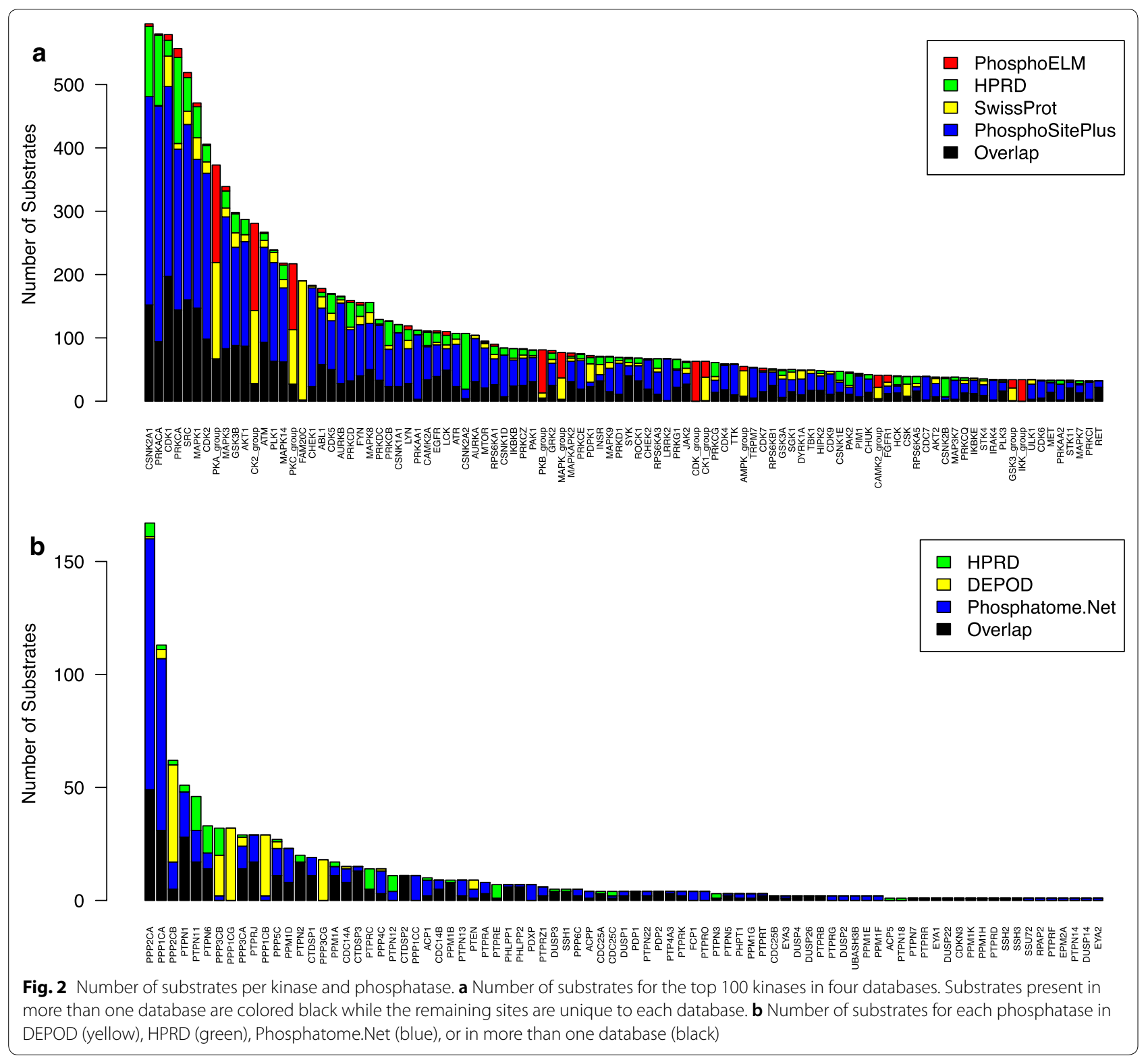

\section{Phosphorylation site prediction tools}

Despite decades of research, very few phosphorylation sites have known kinases or phosphatases. Of the sites in PhosphoSitePlus, only about $3 \%$ have an experimentally validated human kinase. Therefore, numerous tools have been developed to predict which sites in a protein can be phosphorylated and which kinases phosphorylate that given site.

These prediction tools were developed using a variety of features and methods and have been reviewed elsewhere $[47,48]$. The early versions of phosphorylation site predictors were motif-based. They generated the frequency of amino acids surrounding a site and searched for that pattern in protein sequences. Later tools used more sophisticated methods such as support vector machines (SVM), random forest, Bayesian probability, position specific scoring matrices (PSSM), and deep neural networks [49-53]. Besides amino acid sequence, tools included a vast array of features such as the 3D structure of the phosphorylation site, disorder score, cell cycle data, and co-expression of kinases and substrates [54-56]. Others, like NetworKIN and iGPS, used protein-protein interaction data to filter predictions $[57,58]$. Table 3 provides an overview of all currently available tools to predict phosphorylation sites or kinases for phosphorylation sites. While a few tools 
Table 3 Available phosphorylation site and kinase-substrate prediction tools

\begin{tabular}{|c|c|c|c|c|c|c|c|}
\hline Tool & Last update & Version & Prediction type & Method & $\begin{array}{l}\text { Kinases/ } \\
\text { phosphatases }\end{array}$ & Type & References \\
\hline DISPHOS & 2004 & 1.3 & Phosphorylation sites & Bagged logistic regression & 0 & Web & [54] \\
\hline PPSP & 2006 & 1.06 & $\begin{array}{l}\text { Phosphorylation sites of } \\
\text { kinases }\end{array}$ & Bayesian decision theory & 68 & Web & [52] \\
\hline KinasePhos 2.0 & 2007 & 2.0 & $\begin{array}{l}\text { Phosphorylation sites of } \\
\text { kinases }\end{array}$ & SVM & 58 & Web & [51] \\
\hline pkaPS & 2007 & & Phosphorylation sites of PKA & Scoring function & 1 & Web|DL & [72] \\
\hline PhoScan & 2008 & & $\begin{array}{l}\text { Phosphorylation sites of } \\
\text { kinases }\end{array}$ & Scoring function & 48 & Web|Tool & [60] \\
\hline Phos3D & 2009 & & $\begin{array}{l}\text { Phosphorylation sites and } \\
\text { some kinase specificity }\end{array}$ & SVM & 5 & Web & [55] \\
\hline Musite & 2010 & 1 & $\begin{array}{l}\text { Phosphorylation sites and } \\
\text { some kinase specificity }\end{array}$ & SVM & 13 & Web|DL & [62] \\
\hline PHOSIDA Predictor & 2011 & 3.24 & $\begin{array}{l}\text { Phosphorylation } \mathrm{S} \text { and } \mathrm{T} \\
\text { sites }\end{array}$ & SVM & 0 & Web & [26] \\
\hline Predikin & 2011 & & $\begin{array}{l}\text { Phosphorylation sites of } \\
\text { kinases }\end{array}$ & PSSM & any & Web|DL & [53] \\
\hline GPS-Polo & 2012 & 1.0 & Phosphorylation sites of Plk & $\begin{array}{l}\text { Group-based scoring func- } \\
\text { tion PSSM }\end{array}$ & 1 & Web|Tool & [120] \\
\hline iGPS & 2012 & 1.0.1 & $\begin{array}{l}\text { Phosphorylation sites of } \\
\text { kinases in vivo }\end{array}$ & GPS with PPI & 407 & Tool & [57] \\
\hline CEASAR & 2013 & & $\begin{array}{l}\text { Kinases for known phospho- } \\
\text { rylation sites }\end{array}$ & Naïve Bayes & 289 & $\mathrm{DL}$ & [56] \\
\hline HMMPTM & 2013 & & $\begin{array}{l}\text { Phosphorylation sites of } \\
\text { kinases and topology }\end{array}$ & HMM & 9 & Web|DL & [121] \\
\hline PKIS & 2013 & & $\begin{array}{l}\text { Phosphorylation sites of } \\
\text { kinases }\end{array}$ & SVM & 56 & Web & [122] \\
\hline GPS & 2014 & 5.0 & $\begin{array}{l}\text { Phosphorylation sites of } \\
\text { kinases }\end{array}$ & $\begin{array}{l}\text { Group-based scoring func- } \\
\text { tion PSSM }\end{array}$ & 464 & Web|DL|Tool & [61] \\
\hline NetPhorest & 2014 & 2.1 & $\begin{array}{l}\text { Phosphorylation sites of } \\
\text { kinases }\end{array}$ & ANN and PSSM & 244 & Web|DL|Tool & {$[58,65]$} \\
\hline NetworkIN & 2014 & 3.0 & $\begin{array}{l}\text { Phosphorylation sites of } \\
\text { kinases in vivo }\end{array}$ & Naïve Bayes with PPI & 123 & Web|DL|Tool & {$[58,66]$} \\
\hline phos_pred & 2014 & & $\begin{array}{l}\text { Predicts phosphorylation } \\
\text { sites for kinases }\end{array}$ & Random forest & 54 & Tool $^{a}$ & [49] \\
\hline PhosphoSVM & 2014 & & Phosphorylation sites & SVM & 0 & Web & [123] \\
\hline Ptpset & 2014 & & $\begin{array}{l}\text { Dephosphorylation sites of } \\
\text { phosphatases }\end{array}$ & KNN & 3 & Web & {$[124]$} \\
\hline jEcho & 2015 & 1.0 & $\begin{array}{l}\text { Phosphorylation sites of } \\
\text { kinases }\end{array}$ & Weight vector & 12 & Tool & [68] \\
\hline KSP-PUEL & 2015 & & $\begin{array}{l}\text { Phosphorylation sites of } \\
\text { kinases }\end{array}$ & SVM ensemble & $2^{\mathrm{a}}$ & Tool & [63] \\
\hline Scansite & 2015 & 4 & Kinase motifs in proteins & PSSM & 70 & Web|DL & [125] \\
\hline DAPPLE & 2016 & 2 & Phosphorylation sites & BLAST & 0 & Web|DL & [126] \\
\hline ¡Phos-PseEn & 2016 & & Phosphorylation sites & Random forest ensemble & 0 & Web & [127] \\
\hline PhosphoPICK & 2016 & & $\begin{array}{l}\text { Phosphorylation sites of } \\
\text { kinases }\end{array}$ & Bayesian network & 107 & Web|DL & [70] \\
\hline PhosD & 2016 & & $\begin{array}{l}\text { Kinase-substrate relation- } \\
\text { ships }\end{array}$ & Probabilistic model & 399 & $\mathrm{DL}$ & [128] \\
\hline MusiteDeep & 2017 & & $\begin{array}{l}\text { Phosphorylation sites and } \\
\text { some kinase specificity }\end{array}$ & DNN & 5 & Tool $^{\mathrm{a}}$ & [50] \\
\hline NetPhos & 2017 & 3.1 & $\begin{array}{l}\text { Phosphorylation sites and } \\
\text { some kinase specificity }\end{array}$ & ANN & 17 & Web|Tool ${ }^{\mathrm{a}}$ & {$[59,71]$} \\
\hline PhosphoNET & 2017 & & $\begin{array}{l}\text { Phosphorylation sites of } \\
\text { kinases }\end{array}$ & PSSM & 488 & Web & [43] \\
\hline PhosPred-RF & 2017 & & Phosphorylation sites & Random forest & 0 & Web & [129] \\
\hline
\end{tabular}


Table 3 (continued)

\begin{tabular}{|c|c|c|c|c|c|c|c|}
\hline Tool & Last update & Version & Prediction type & Method & $\begin{array}{l}\text { Kinases/ } \\
\text { phosphatases }\end{array}$ & Type & References \\
\hline AKID & 2018 & & $\begin{array}{l}\text { Phosphorylation sites of } \\
\text { kinases }\end{array}$ & DNN & 496 & Web|DL|Tool ${ }^{\mathrm{a}}$ & [69] \\
\hline CapsNet_PTM & 2018 & & $\begin{array}{l}\text { Phosphorylation sites and } \\
\text { some kinase specificity }\end{array}$ & DNN & any & Tool & [130] \\
\hline PTM-ssMP & 2018 & & $\begin{array}{l}\text { Phosphorylation sites and } \\
\text { some kinase specificity }\end{array}$ & SVM & 9 & Web|DL & [131] \\
\hline Quokka & 2018 & & $\begin{array}{l}\text { Phosphorylation sites of } \\
\text { kinase families }\end{array}$ & Logistic regression & 65 & Web|DL & [132] \\
\hline TyrPred & 2018 & & $\begin{array}{l}\text { Phosphorylation sites of Tyr } \\
\text { kinases }\end{array}$ & Elastic net & 15 & Web & [133] \\
\hline CoPhosk & 2019 & & $\begin{array}{l}\text { Kinases of phosphorylation } \\
\text { sites }\end{array}$ & Naïve Bayes & 101 & Web|Tool & [134] \\
\hline DeepPhos & 2019 & & $\begin{array}{l}\text { Phosphorylation sites and } \\
\text { some kinase specificity }\end{array}$ & DNN & 20 & Tool & [67] \\
\hline
\end{tabular}

a Indicates number of trained kinases, but tool can be trained with others

SVM support vector machine, PSSM position specific scoring matrix, GSEA gene set enrichment analysis, ANN artificial neural network, DNN deep neural network, HMM hidden Markov model, $P P I$ protein-protein interaction, KNN K-nearest neighbor

a Indicates tool is not available for all three main operating systems (Linux, Mac, Windows)

have been developed to predict sites for phosphatases, only Ptpset, NetPhorest, and NetworKIN are still accessible $[49,58]$.

Figure 3 shows phosphorylation site predictor tools and the resources they used to make predictions. Almost all phosphorylation site predictors were trained using data from Phospho.ELM. Swiss-Prot and PhosphoSitePlus were also heavily used resources. Notably, almost all tools were developed using experimentally verified substrate data as the training set. Therefore, the tools are only able to predict the responsible kinase if there is sufficient data for substrates of that kinase.

A researcher may utilize these prediction tools to identify kinases phosphorylating single substrates of interest, for which web-based tools would suffice. However, the limit on the number of sequences submitted for prediction and the lack of downloadable results prevent these same tools for being useful in large-scale phosphoproteomic studies. Unfortunately, many tools appropriate for large-scale studies have multiple issues limiting their use. First, tools can be difficult to install, platform-specific, and lack manuals on use. For example, NetPhos [59] is downloadable but can only be run on Linux, whereas PhoScan [60] can only be run on Windows machines. Other tools require commercial software such as MAT$\mathrm{LAB}$ or even require understanding a programming language to modify hard-coded variables. Finally, tools like GPS [61] and phos_pred [49] provide pre-defined cutoffs for prediction, while others like musite [62] and KSPPUEL [63] allow users to define their own thresholds or to train the models using their own data.

\section{Testing kinase-substrate relationship prediction tools}

For large-scale kinase-substrate prediction, 14 pretrained tools were available that provide downloadable results. The best, unbiased way to test these tools is to use validated sites that were not used for the training of any tool. Unfortunately, most tools do not report the actual sites used for training and finding a set of sites to fit these criteria is nearly impossible. Therefore, we evaluated all 14 tools using gold-standard positive and negative human phosphorylation sites downloaded from dbPTM [64] for four serine/threonine kinases (CDK1, CK2, MAPK1, and PKA). Positive sites were serines and threonines experimentally validated to be phosphorylated by a particular kinase. Negative sites were serines and threonines not known to be phosphorylated on the same proteins. The outcomes might be biased in favor of newer tools and those that used some of these sites in their training.

Tools predicting kinases for phosphorylation sites (Table 3) were accessed through local tool installation or through the tool's website. PhoScan [60] and phos pred [49] were run locally on a Windows laptop, while NetPhorest [65], NetworKIN [66], iGPS [57], GPS [61], DeepPhos [67], jEcho [68], and MusiteDeep [50] were run locally on a Mac laptop. AKID [69], PhosphoPICK [70], NetPhos [71], Musite [62], and pkaPS [72] were accessed via their websites. Tools were set with the lowest threshold if they did not have an option to return scores for all sites. For each site, the maximum score was retained if the tool predicted for more than kinase isoform (e.g., the maximum score of PKCalpha and PKCbeta on the same site). If a tool did not return 


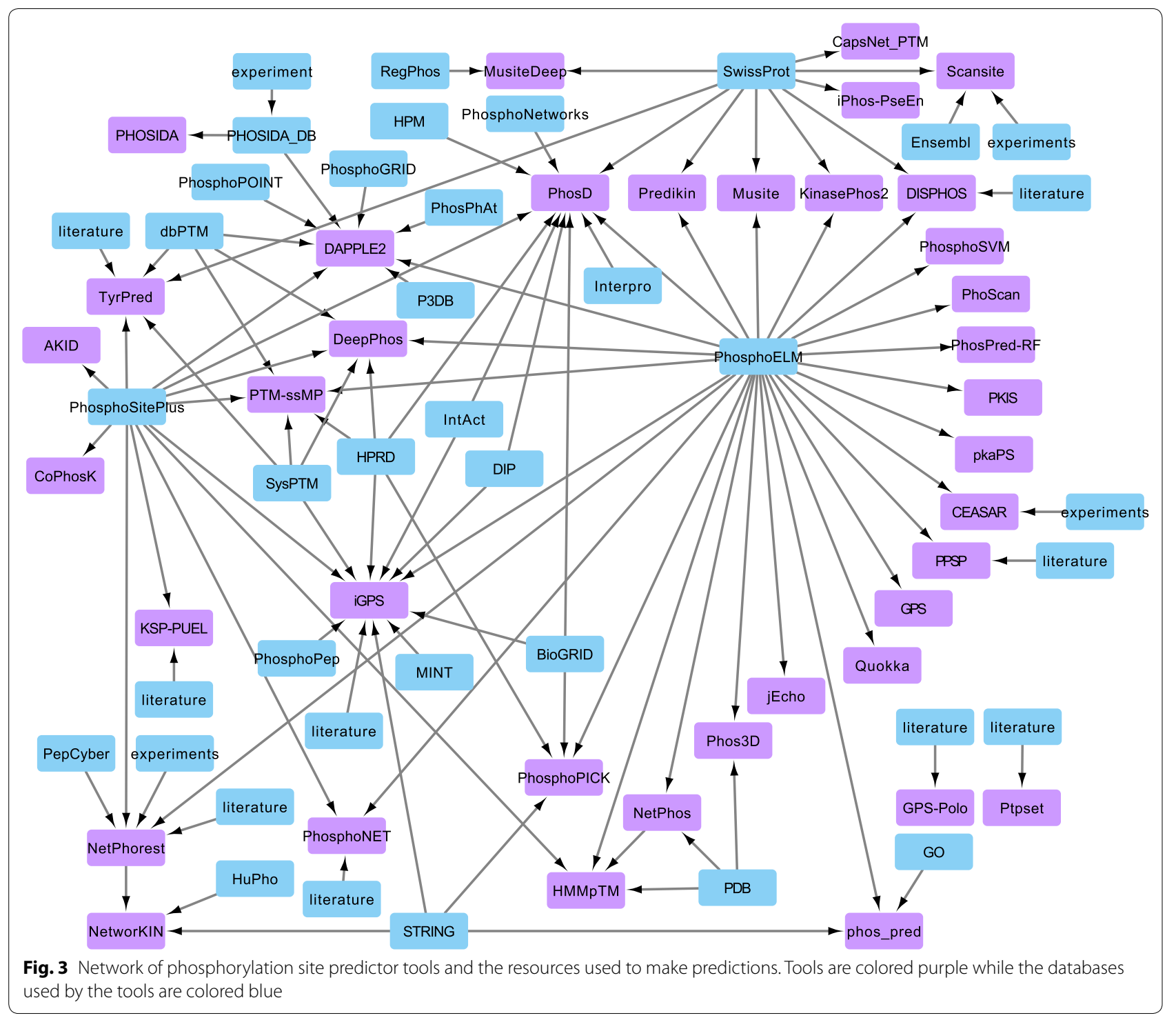

a score for a site, the lowest possible score was given to the site. The receiver operating characteristic (ROC) curve and area under the ROC curve (AUROC) were calculated for the results from each tool using the $\mathrm{R}$ package ROCR [73].

ROC curves for four kinases (CDK1, CK2, MAPK1, and PKA) are shown in Fig. 4. Notably, musite was unable to predict for a few random protein sequences in each submission. DeepPhos and phos_pred both required manual edits of hard-coded variables. MusiteDeep and GPS had the highest area under the curve (AUC) for all kinases tested. The PKA-specific tool pkaPS also performed well. Performance for most tools, however, varied across kinases.

\section{Comparison of kinase activity tools}

The known or predicted kinases for phosphorylation sites can be used to infer kinase activity from global phosphoproteomic data. Tools and methods have been developed to predict kinase activity, but there has been little effort spent towards comparing these tools or determining the most biologically-relevant set of parameters. The available tools (PHOSIDA, KEA2, KSEA App, PHOXTRACK, INKA, and IKAP) each use a different algorithm to infer activity (Table 4). The PHOSIDA de novo motif finder uses a simple method of bootstrapping to determine enrichment of sequence motifs in a set of phosphorylated peptides and then matches those to known kinase motifs [26]. Kinase Enrichment Analysis 2 (KEA2) uses 

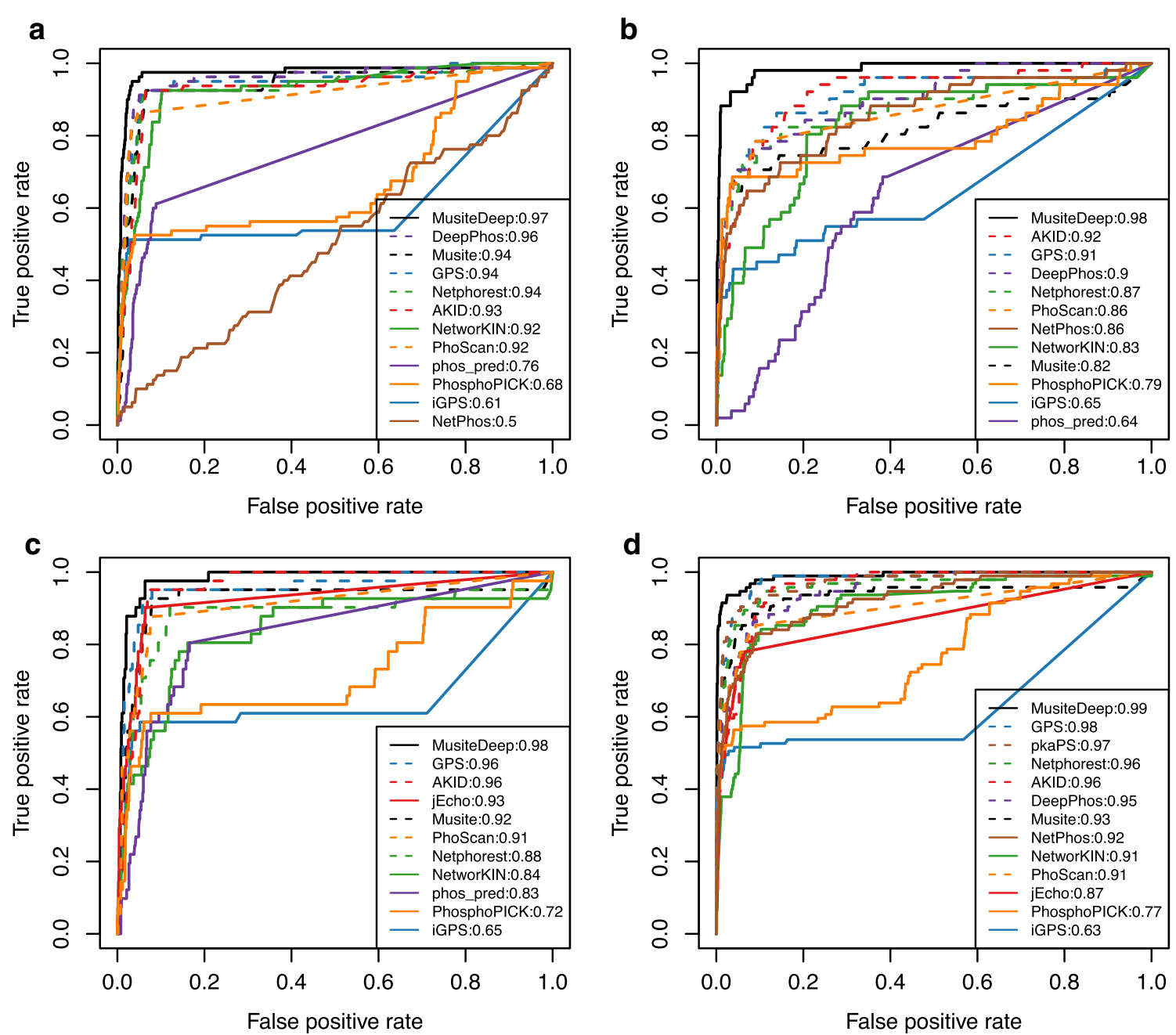

Fig. 4 ROC curves for substrate prediction of four kinases. The false positive and true positive rates of substrate prediction for a CDK1, b CK2, $\mathbf{c}$ MAPK1, and $\mathbf{d}$ PKA. The AUC for each tool is listed next to the tool name

over-representation analysis to determine enrichment of kinase substrates in a condition [74]. Similarly, the KSEA App uses mean phosphorylation of substrates of kinases as a proxy for activity [4]. PHOXTRACK modified preranked gene set enrichment analysis (GSEA) to determine enrichment of known kinase targets [75]. IKAP extended these methods using a cost function to infer the relative contributions of multiple kinases acting on the same site [76]. Finally, INKA combines the GSEA method with activating phosphorylation on kinases [77].

We used a phosphoproteomic dataset from a cell line experiment with 20 kinase inhibitors [78] to test four kinase activity prediction tools. Because PHOSIDA is only available online without downloadable results, we excluded this tool from further analysis. INKA was also excluded as it requires MaxQuant search result files. The $\mathrm{R}$ programming environment was used to create files in the input format for each tool. Significantly downregulated sites for each inhibitor were submitted to KEA2 and significantly inhibited kinases were defined as those with false discovery rate (FDR) $<0.05$ and at least 3 overlapping substrates [74]. The log2 fold change for each thirteenmer phosphorylation site $( \pm 6$ amino acids surrounding the phosphorylated site) was submitted to PHOXTRACK (1000 permutations, minimum number of substrates $=3$, weighted statistics) [75]. Significantly inhibited kinases were defined as those with FDR $<0.05$ and normalized enrichment value $<0$. The fold change for each site with each inhibitor was submitted to the KSEA app website and significantly inhibited kinases were defined as those with $\mathrm{FDR}<0.05$, at least 3 substrates in the dataset, and a $\mathrm{z}$ score $<0$ [4]. The substrates of kinases from PhosphoSitePlus (version July 2017) and Signor (version October 2017) were used for IKAP [23, 34, 76]. IKAP was run 
Table 4 Kinase activity prediction and phosphoproteomic dataset analysis tools

\begin{tabular}{|c|c|c|c|c|c|c|}
\hline Tool & Last update & Prediction type & Method & Input & Type & References \\
\hline PHOSIDA Motif Finder & 2011 & Sequence motifs & Bootstrap & Phosphosite 13mer & Web & {$[26]$} \\
\hline CellNOpt & 2012 & Time-course analysis & Logic formalisms & $\begin{array}{l}\text { Interactions and phospho- } \\
\text { proteomic data }\end{array}$ & Tool & {$[85]$} \\
\hline KEA2 & 2012 & Kinase activity & Fisher's exact test & $\begin{array}{l}\text { Gene symbols and phos- } \\
\text { phosite }\end{array}$ & Web|DL|Tool & {$[74]$} \\
\hline Sorad & 2013 & Time-course analysis & $\begin{array}{l}\text { Ordinary differential equa- } \\
\text { tions }\end{array}$ & Phosphoproteomic data & Tool & {$[86]$} \\
\hline PHOXTRACK & 2014 & Kinase activity & GSEA & $\begin{array}{l}\text { Phosphosite } 13 \text { mer and } \\
\text { log2 expression }\end{array}$ & Web|DL & {$[75]$} \\
\hline PhosFox & 2015 & $\begin{array}{l}\text { Phosphorylation site } \\
\text { comparison between } \\
\text { groups }\end{array}$ & Comparison & Phosphoproteomic data & Tool & {$[84]$} \\
\hline SELPHI & 2015 & $\begin{array}{l}\text { Phosphoproteomic data } \\
\text { analysis }\end{array}$ & Multiple functions & Phosphoproteomic data & Web|DL & [83] \\
\hline DynaPho & 2016 & $\begin{array}{l}\text { Phosphoproteomic } \\
\text { analysis for multiple } \\
\text { conditions }\end{array}$ & Activity modules & phosphoproteomic data & Web|DL & {$[87]$} \\
\hline IKAP & 2016 & Kinase activity & Cost function & Phosphoproteomic data & Tool & {$[76]$} \\
\hline KinasePA & 2016 & $\begin{array}{l}\text { Kinase perturbation in } \\
\text { multiple treatments }\end{array}$ & $\begin{array}{l}\text { Directional hypothesis } \\
\text { testing framework }\end{array}$ & Phosphoproteomic data & Web|Tool & {$[88]$} \\
\hline KSEA & 2017 & Kinase activity & Z score & Phosphoproteomic data & Web|DL|Tool & {$[4]$} \\
\hline CLUE & 2018 & $\begin{array}{l}\text { Time-course kinase } \\
\text { activity }\end{array}$ & k-Means clustering & Phosphoproteomic data & Tool & {$[41]$} \\
\hline INKA & 2019 & Kinase activity & $\begin{array}{l}\text { GSEA and phosphoryla- } \\
\text { tion }\end{array}$ & Phosphoproteomic data & Web|DL & {$[77]$} \\
\hline
\end{tabular}

GSEA gene set enrichment analysis

locally on a Mac laptop with the bounds between -11 and 11 and 50 iterations. The 5 kinases with the lowest activity scores for each experiment were chosen. The positive set were kinases known to be inhibited by each drug (as reported in supplementary table in Ref. [78]); all other kinases predicted by the tools were considered to be negative. The significant kinases for each tool were counted for presence in the positive and negative sets.

Comparison of these tools is challenging because they use different input and underlying databases. KEA2 requires a set of sites in the format of HGNC symbol and phosphorylated amino acid residue position separated by an underscore. It contains sets for 250 different kinases. KSEA App requires a strictly formatted comma-delimited file with the HGNC symbol, phosphorylated position, and non-log-transformed fold change. Users can choose between known sets from the July 2016 release of PhosphoSitePlus or the known + predicted site sets from PhosphoSitePlus and NetworKIN. PHOXTRACK requires a two-column file with a thirteenmer peptide and log-transformed fold change. It can use substrate sets from the four main databases or a user-supplied database. Finally, IKAP required tabular data entered into MATLAB, manual modification of MATLAB code to change parameters, and allowed a user to upload their own set of substrates. Because one thirteenmer might match multiple proteins and phosphorylated positions, the actual substrate list presented to each tool may differ slightly.

To determine how well each tool covered the known targets of kinases, we counted the number of significantly downregulated known kinases of each inhibitor and the significantly downregulated kinases of each inhibitor that were not known targets of that inhibitor. The KSEA App made the most true positive predictions across all experiments, while IKAP made the fewest true positive predictions (Fig. 5a). PHOXTRACK made the fewest false positive predictions (Fig. $5 \mathrm{~b}$ ).

Besides upstream kinase activity, phosphoproteomics data could additionally be used to explore altered downstream pathways. While standard tools and methods such as GSEA are typically used for this analysis, all are limited to using overall gene-level phosphorylation [79]. Unfortunately the functional contribution of individual sites to pathway signaling is poorly annotated in gene set databases, although PTMsigDB has some limited pathway sets [80]. Until new tools are built to handle individual sites in pathway analysis, a user might combine the results from kinase activity prediction to assemble 

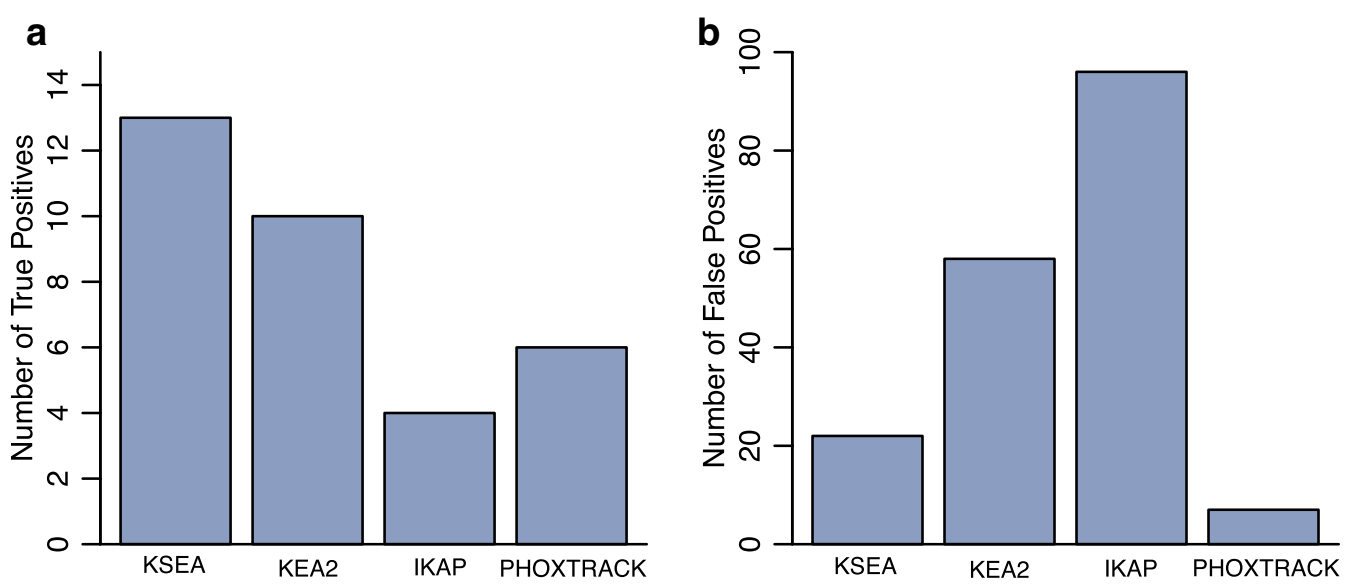

Fig. 5 True and false positive predictions for kinase activity prediction tools. a For all 20 inhibitors, the number of known targets predicted to be significantly downregulated by each tool. $\mathbf{b}$ For all inhibitors, the number of all significantly downregulated kinases that do not match known inhibitor targets

altered kinases into pathways using tools such as String, RegPhos2, or Wikipathways [42, 81, 82].

\section{Differential and clustering analysis of phosphoproteomics data}

Besides activity prediction, phosphoproteomic data can be used for other analyses. SELPHI is a good tool to first explore the data as it allows biologists to quickly and easily analyze phosphoproteomic data with clustering analyses, kinase-substrate correlation, and pathway enrichment [83]. PhosFox then compares phosphorylated peptides between conditions [84]. Finally, a set of tools (CellNOpt, Sorad, CLUE, DynaPho, and KinasePA) were developed specifically for phosphoproteomic time-course or multiple condition analyses (Table 4) [41, 85-88].

\section{Prediction of mutation effect}

Analysis and interpretation of phosphoproteomic data can be enhanced with other multi-omics data types. For example, sequence variants can affect kinase function or presence of a phosphorylation site. The databases
PhosSNP [89] and ActiveDriverDB [90] collect gene polymorphisms and somatic mutations, respectively, near phosphorylation sites and categorize them based on suspected effect (Table 5). ActiveDriverDB also includes predictions from Mutations Impact on Phosphorylation (MIMP), which uses Bayesian statistics to predict whether mutations around a phosphorylation site will change which kinase binds to that site [91]. It can predict rewiring for 124 kinases using experimentally validated data, or it can be extended to predict for 322 kinases using predicted kinase-substrate relationships. ReKINect also predicts rewiring from mutations, but it further predicts the destruction or creation of phosphorylation sites and inactivation or constitutive activation of kinases [92]. PhosphoPICK-SNP is also similar to MIMP. It predicts the kinase responsible for phosphorylating a site, and whether a mutation affects its ability to phosphorylate the site [93]. While all of the tools are easy to use, the databases are better for individual searches and the three prediction tools are better for analysis of a user's mutation data.

Table 5 Resources for studying the effect of mutations on kinases and phosphorylation sites

\begin{tabular}{|c|c|c|c|c|c|c|c|}
\hline Tool & Last update & Version & Prediction type & Method & Kinases & Method of access & References \\
\hline PhosSNP & 2009 & 1.0 & $\begin{array}{l}\text { SNVs that might influence phosphoryla- } \\
\text { tion status }\end{array}$ & Rules & & Tool & [89] \\
\hline MIMP & 2015 & & Missense SNV impact on kinase-substrate & Bayesian model & 322 & Web|DL|Tool & {$[91]$} \\
\hline ReKINect & 2015 & & Effect of SNV on signaling network & PSSM & & Web|DL & [92] \\
\hline PhosphoPICK-SNP & 2016 & & Effect of SNV on phosphorylation level & Bayesian models & 107 & Web|DL & [93] \\
\hline ActiveDriverDB & 2017 & & $\begin{array}{l}\text { Somatic variants affecting phosphoryla- } \\
\text { tion }\end{array}$ & Rules & 322 & Web|DL & {$[90]$} \\
\hline
\end{tabular}




\section{Resources for kinase inhibitors}

After discovering altered kinases from phosphoproteomic data to use as therapeutic targets, identifying inhibitors is essential. Most available resources connect known drugs to their known kinase targets (Table 6). DrugKiNET shows the known inhibitors for kinases, and the kinases that a compound inhibits. It also predicts which kinases a drug can inhibit. K-Map extends these interactions to suggest the best compound to inhibit a set of kinases [94]. Finally, KinomeSelector groups kinases by sequence similarity and similarity of drug response. It then allows a user to choose a subset of kinases to target that cover the kinome [58].

\section{Other kinase signaling tools}

The final set of bioinformatics tools, summarized in Table 7, enhance phosphoproteomic analysis and cover visualization, data retrieval, and prediction tools.
Additional kinases from a genome can be predicted by Kinannote [95] and KinConform can predict whether those kinases are active in structure files [96]. KinMap [97] is used to visualize the entire kinome tree and PhosphoLogo [98] is used to generate sequence logos of kinases. On the other side, RLIMS-P and eFIP are both tools that extract data on phosphorylation interactions from the literature $[99,100]$. Then CPhos identifies phosphorylation sites of interest that are conserved across species [101]. PyTMs [102] is a tool to visualize 3D structures of phosphorylation sites and ultimately RegPhos2.0 [42] can be used to visualize signaling networks. RegPhos 2.0 also provides heatmaps for kinase and substrate mRNA expression in cancer. Finally, 14-3-3-Pred predicts phosphorylation sites in protein sequences that might bind to $14-3-3$ proteins, further adding to the phosphorylation-related signaling network [103].

Table 6 Kinase-inhibitor relationship resources

\begin{tabular}{|c|c|c|c|c|c|c|}
\hline Tool & Last update & Description & Kinases & Inhibitors & Method of access & References \\
\hline K-Map & 2013 & Best inhibitor for a set of kinases & 300 or 442 & 178 or 72 & Web|DL & [94] \\
\hline KinomeSelector & 2014 & Minimal set of kinases to inhibit & $>500$ & NA & Web|DL & {$[58]$} \\
\hline DrugKiNET & 2017 & $\begin{array}{l}\text { Known and predicted drug activity } \\
\text { on kinases }\end{array}$ & $>800$ & & Web|DL & \\
\hline
\end{tabular}

K-Map has two different databases-one with 178 drugs inhibiting 300 kinases and one with 72 drugs inhibiting 442 kinases

Table 7 Visualization, data retrieval, and prediction tools

\begin{tabular}{|c|c|c|c|c|c|c|c|}
\hline Tool & Last update & Version & Type & Input & Output & Method of access & References \\
\hline CPhos & 2012 & 1.3 & $\begin{array}{l}\text { Phosphorylation site } \\
\text { conservation }\end{array}$ & Phosphopeptides & Conservation scores & Tool & {$[101]$} \\
\hline PhosphoLogo & 2012 & & $\begin{array}{l}\text { Visualization of } \\
\text { sequence motifs }\end{array}$ & Sequence motifs & Motif visualization & Tool & {$[98]$} \\
\hline RegPhos2.0 & 2013 & 2.0 & $\begin{array}{l}\text { Visualization of kinase } \\
\text { data }\end{array}$ & Gene names & $\begin{array}{l}\text { Network visualization or } \\
\text { cancer gene expres- } \\
\text { sion }\end{array}$ & Web|DL & {$[42,113]$} \\
\hline eFIP & 2014 & & $\begin{array}{l}\text { Returns publications } \\
\text { involving phospho- } \\
\text { rylation }\end{array}$ & Gene names or words & $\begin{array}{l}\text { Publications matching } \\
\text { those words }\end{array}$ & Web & {$[100]$} \\
\hline RLIMS-P & 2014 & 2.0 & $\begin{array}{l}\text { returns protein phos- } \\
\text { phorylation informa- } \\
\text { tion from literature }\end{array}$ & PMIDs or keywords & $\begin{array}{l}\text { kinase, substrate, and } \\
\text { site }\end{array}$ & Web|DL & [99] \\
\hline PyTMs & 2015 & 1.2 & $\begin{array}{l}\text { pyMOL plugin to add } \\
\text { PTMs to protein } \\
\text { models }\end{array}$ & Protein models, PTMs & $\begin{array}{l}\text { PTMs integrated in } \\
\text { protein models }\end{array}$ & Tool & {$[102]$} \\
\hline 14-3-3-Pred & 2015 & & $\begin{array}{l}\text { Predicts } 14-3-3 \text { binding } \\
\text { phosphosite }\end{array}$ & Protein sequences & $\begin{array}{l}\text { Predicted 14-3-3 bind- } \\
\text { ing sites }\end{array}$ & Web|DL & [103] \\
\hline KinMap & 2016 & & $\begin{array}{l}\text { Kinome tree visualiza- } \\
\text { tion }\end{array}$ & Kinases & $\begin{array}{l}\text { Tree with highlighted } \\
\text { branches }\end{array}$ & Web|DL & {$[97]$} \\
\hline KinConform & 2017 & & $\begin{array}{l}\text { Determines which struc- } \\
\text { tures are kinases }\end{array}$ & Structures & $\begin{array}{l}\text { Active or inactive kinase } \\
\text { chains }\end{array}$ & Tool & [96] \\
\hline Kinannote & 2017 & 1.0 & $\begin{array}{l}\text { Classifies sequences as } \\
\text { kinases }\end{array}$ & Protein sequences & Kinase annotation & Tool & {$[95]$} \\
\hline
\end{tabular}




\section{Discussion}

The available databases and tools for studying kinase signaling cover diverse functions and include information on enzymes and their substrates, inhibitors, activity, and mutations. Together these knowledge bases, prediction tools, and analysis tools comprise the current best standard for studying kinase signaling and many can be used without extensive computational knowledge. Overall, these tools allow a researcher to discover vast amounts of information from their phosphoproteomic data and some tools can even perform entire sets of analyses with a single button click [83].

Despite the work that has been done, there is room for advancement to fully utilize phosphoproteomic data for use in the clinic. First, the majority of tools focus almost exclusively on the study of protein kinases. However, phosphatases are critical components of the kinase signaling cascade and are frequently dysregulated in cancer. Understanding the role of the interplay between kinases and phosphatases on the net phosphorylation seen in global phosphoproteomic data is essential to identifying abnormal cell signaling in disease. Furthermore, while the current tools and research are aimed at studying dysregulated protein phosphorylation, non-protein phosphorylation is also often altered in disease. For example, hexokinases, which phosphorylate glucose, drive glucose metabolism and contribute to tumor initiation in mouse models of lung and breast cancers [104]. The development of resources and tools to study non-protein kinases and phosphatases could advance research in a variety of fields.

While the current tools provide critical functions, their error rate and accuracy could be improved. Errors are frequently propagated or amplified when tools collect data from a variety of resources. However, the impact of these errors on downstream analyses and biological inferences remains to be determined.

For all tools, usability can be an issue, both for bioinformaticians and biologists with no computational experience. Tools are frequently platform-dependent, do not allow downloadable results, and are not well annotated. Furthermore, tools are difficult to compare or to use more than one during analysis. The input and output formats are not standardized and use a variety of protein naming conventions.

The largest challenge was deciphering input limitations and understanding results. For example, submitting a sequence with a large number of phosphorylatable residues to GPS caused the software to stall without an error message and no documentation mentioned a size limit. Musite did not provide results for a sequence or two each run without explanation. Furthermore, downloadable result files for many tools had no column headers so the column contents were unknown. For example, the downloadable file from musite has no column titles, so you have to check the table on the website to understand the results. Additionally, scores are usually presented without explanation. Only careful reading of the manuscript or the manual elucidates what value signifies a "good" response. For example, in Scansite, the score 0 is the best, with scores closest to 0 indicating the best match. But in PhosphoPICK, the score indicates the probability of being phosphorylated by a kinase at that site so a score closer to 1 is better. Experts in machine learning might understand the score without explanation, but naïve users likely will not.

One way to fix this challenge is to have a detailed, easy-to-find manual. The manual should include ways to run the tool, the underlying mechanism of the method, and detailed description of the results. The description of the results should also be available where results are visualized. Furthermore, sample input is helpful for a new user to test the tool and determine whether the results will be useful for their experiment before preparing their own data files.

\section{Conclusions}

There are many tools and resources that can be used to study kinase signaling and these tools will become even more essential with the continued production of phosphoproteomic data. It is essential for the biological community to research under-studied enzymes and to validate specific substrates of kinases and phosphatases. Furthermore, bioinformaticians should consider creating tools that utilize information from both sides of the enzymatic phosphorylation reaction. Finally, resources should be carefully planned, easy to use, and well maintained and the community should work to standardize the use of enzyme IDs and phosphorylation site location.

\section{Supplementary information}

Supplementary information accompanies this paper at https://doi. org/10.1186/s12014-020-09290-x.

Additional file 1. List of URLS for all resources.

\section{Abbreviations}

ANN: Artificial neural network; AUC: Area under the curve; AUROC: Area under the ROC curve; DL: Downloadable; FDR: False discovery rate; GSEA: Gene set enrichment analysis; HMM: Hidden Markov model; HT: High-throughput; LT: Low-throughput; MELK: Maternal embryonic leucine zipper kinase; PDK1: Pyruvate dehydrogenase kinase 1; PDPK1: 3-Phosphoinositide-dependent protein kinase 1; PEG: Paternally expressed gene 3; PPI: Protein-protein interaction; PSSM: Position specific scoring matrix; PTM: Post-translational modification; ROC: Receiver operating characteristic; SVM: Support vector machine; Web: Website. 


\section{Acknowledgements}

The authors thank Bo Wen for his help in installation and execution of the deep learning tools.

\section{Authors' contributions}

SRS designed, analyzed, and drafted the review. BZ guided the study and contributed to the revision of the review. Both authors read and approved the final manuscript.

\section{Funding}

This work was supported by National Institutes of Health Grants

T15-LM007450 and U24CA210954, by Grant CPRIT RR160027 from the Cancer Prevention \& Research Institutes of Texas (CPRIT), and by funding from the McNair Medical Institute at The Robert and Janice McNair Foundation. BZ is a CPRIT Scholar in Cancer Research and a McNair Scholar.

\section{Availability of data and materials}

The data used for comparing kinase activity inference tools can be found in PubMed with PMID: 28674151.

\section{Ethics approval and consent to participate}

Not applicable.

\section{Consent for publication}

Not applicable.

\section{Competing interests}

The authors declare that they have no competing interests.

\section{Author details}

${ }^{1}$ Department of Biomedical Informatics, Vanderbilt University, Nashville, TN, USA. ${ }^{2}$ Lester and Sue Smith Breast Center, Baylor College of Medicine, Houston, TX, USA. ${ }^{3}$ Department of Molecular and Human Genetics, Baylor College of Medicine, Houston, TX, USA

Received: 1 December 2019 Accepted: 4 July 2020

Published online: 11 July 2020

\section{References}

1. Olow A, Chen Z, Niedner RH, Wolf DM, Yau C, Pankov A, et al. An atlas of the human kinome reveals the mutational landscape underlying dysregulated phosphorylation cascades in cancer. Cancer Res. 2016;76(7):1733-45.

2. Bhullar KS, Lagarón NO, McGowan EM, Parmar I, Jha A, Hubbard BP, et al. Kinase-targeted cancer therapies: progress, challenges and future directions. Mol Cancer. 2018;17:1-20.

3. Hernandez-Armenta C, Ochoa D, Gonçalves E, Saez-Rodriguez J, Beltrao P. Benchmarking substrate-based kinase activity inference using phosphoproteomic data. Bioinformatics. 2017;33(12):1845-51.

4. Wiredja DD, Koyutürk M, Chance MR. The KSEA App: a web-based tool for kinase activity inference from quantitative phosphoproteomics. Bioinformatics. 2017;33:3489-91.

5. Henry VJ, Bandrowski AE, Pepin A-S, Gonzalez BJ, Desfeux A. OMICtools: an informative directory for multi-omic data analysis. Database. 2014:2014:bau069. https://doi.org/10.1093/database/bau069.

6. Wang Y, Liu Z, Cheng H, Gao T, Pan Z, Yang Q, et al. EKPD: a hierarchical database of eukaryotic protein kinases and protein phosphatases. Nucleic Acids Res. 2014;42(Database issue):D496-502.

7. Manning G, Whyte DB, Martinez R, Hunter T, Sudarsanam S. The Protein kinase complement of the human genome. Science. 2002;298(5600):1912-34.

8. Martin DMA, Miranda-Saavedra D, Barton GJ. Kinomer v 1.0: a database of systematically classified eukaryotic protein kinases. Nucleic Acids Res. 2009:37(Database issue):D244-50.

9. Krupa A, Abhinandan KR, Srinivasan N. KinG: a database of protein kinases in genomes. Nucleic Acids Res. 2004;32(Database issue):D153-5.
10. Ortutay C, Väliaho J, Stenberg K, Vihinen M. KinMutBase: a registry of disease-causing mutations in protein kinase domains. Hum Mutat. 2005;25(5):435-42

11. Milanesi L, Petrillo M, Sepe L, Boccia A, D'Agostino N, Passamano M, et al. Systematic analysis of human kinase genes: a large number of genes and alternative splicing events result in functional and structural diversity. BMC Bioinform. 2005;6(4):S20.

12. McSkimming DI, Dastgheib S, Talevich E, Narayanan A, Katiyar S, Taylor SS, et al. ProKinO: a unified resource for mining the cancer kinome. Hum Mutat. 2015;36(2):175.

13. Guo Y, Peng D, Zhou J, Lin S, Wang C, Ning W, et al. iEKPD 2.0: an update with rich annotations for eukaryotic protein kinases, protein phosphatases and proteins containing phosphoprotein-binding domains. Nucleic Acids Res. 2018;47:D344-50.

14. Richardson CJ, Gao Q, Mitsopoulous C, Zvelebil M, Pearl LH, Pearl FMG. MoKCa database-mutations of kinases in cancer. Nucleic Acids Res. 2009;37(Database issue):D824-31.

15. Simonetti FL, Tornador C, Nabau-Moretó N, Molina-Vila MA, MarinoBuslje C. Kin-Driver: a database of driver mutations in protein kinases. Database. 2014;2014:bau104. https://doi.org/10.1093/database/bau10 4.

16. van Linden OPJ, Kooistra AJ, Leurs R, de Esch IJP, de Graaf C. KLIFS: a knowledge-based structural database to navigate kinase-ligand interaction space. J Med Chem. 2014;57(2):249-77.

17. Chiu Y-Y, Lin C-T, Huang J-W, Hsu K-C, Tseng J-H, You S-R, et al. KIDFamMap: a database of kinase-inhibitor-disease family maps for kinase inhibitor selectivity and binding mechanisms. Nucleic Acids Res. 2013;41(Database issue):D430-40.

18. Liberti S, Sacco F, Calderone A, Perfetto L, lannuccelli M, Panni S, et al. HuPho: the human phosphatase portal. FEBS J. 2013;280(2):379-87.

19. Duan G, Li X, Köhn M. The human DEPhOsphorylation database DEPOD: a 2015 update. Nucleic Acids Res. 2015;43(Database issue):D531-5.

20. Chen MJ, Dixon JE, Manning G. Genomics and evolution of protein phosphatases. Sci Signal. 2017;10(474):eaag1796.

21. Keshava Prasad TS, Goel R, Kandasamy K, Keerthikumar S, Kumar S, Mathivanan S, et al. Human Protein Reference Database-2009 update. Nucleic Acids Res. 2009;37(Database issue):D767-72.

22. The UniProt Consortium. UniProt: the universal protein knowledgebase Nucleic Acids Res. 2017;45(D1):D158-69.

23. Hornbeck PV, Zhang B, Murray B, Kornhauser JM, Latham V, Skrzypek E. PhosphoSitePlus, 2014: mutations, PTMs and recalibrations. Nucleic Acids Res. 2015:43(Database issue):D512-20.

24. Dinkel H, Chica C, Via A, Gould CM, Jensen LJ, Gibson TJ, et al. Phospho. ELM: a database of phosphorylation sites-update 2011. Nucleic Acids Res. 2011;39(Database issue):D261-7.

25. Nagai T, Yoshimoto J, Kannon T, Kuroda K, Kaibuchi K. Phosphorylation signals in striatal medium spiny neurons. Trends Pharmacol Sci. 2016;37(10):858-71.

26. Gnad F, Gunawardena J, Mann M. PHOSIDA 2011: the posttranslational modification database. Nucleic Acids Res. 2011;39(Database issue):D253-60.

27. Nguyen TD, Vidal-Cortes O, Gallardo O, Abian J, Carrascal M. LymPHOS 2.0: an update of a phosphosite database of primary human T cells. Database. 2015;2015:bav115. https://doi.org/10.1093/database/bav115.

28. Lawrence RT, Searle BC, Llovet A, Villén J. "Plug-and-play" investigation of the human phosphoproteome by targeted high-resolution mass spectrometry. Nat Methods. 2016;13(5):431-4.

29. Giansanti P, Aye TT, van den Toorn H, Peng M, van Breukelen B, Heck AJR. An augmented multiple-protease-based human phosphopeptide atlas. Cell Reports. 2015;11(11):1834-43.

30. Bodenmiller B, Malmstrom J, Gerrits B, Campbell D, Lam H, Schmidt A, et al. PhosphoPep - a phosphoproteome resource for systems biology research in Drosophila Kc167 cells. Mol Syst Biol. 2007;3:139.

31. Bodenmiller B, Campbell D, Gerrits B, Lam H, Jovanovic M, Picotti P, et al. PhosphoPep - a database of protein phosphorylation sites in model organisms. Nat Biotechnol. 2008;26(12):1339-40.

32. Beltrao $P$, Albanèse $V$, Kenner LR, Swaney DL, Burlingame A, Villén J, et al. Systematic functional prioritization of protein posttranslational modifications. Cell. 2012;150(2):413-25. 
33. Yu K, Zhang Q, Liu Z, Zhao Q, Zhang X, Wang Y, et al. qPhos: a database of protein phosphorylation dynamics in humans. Nucleic Acids Res. 2018:8:D451-8.

34. Perfetto L, Briganti L, Calderone A, Cerquone Perpetuini A, lannuccelli M, Langone F, et al. SIGNOR: a database of causal relationships between biological entities. Nucleic Acids Res. 2016;44(D1):D548-54.

35. Tinti M, Madeira F, Murugesan G, Hoxhaj G, Toth R, Mackintosh C. ANIA: annotation and integrated analysis of the 14-3-3 interactome. Database. 2014;2014:085.

36. Hu J, Rho H-S, Newman RH, Zhang J, Zhu H, Qian J. PhosphoNetworks: a database for human phosphorylation networks. Bioinformatics. 2014;30(1):141-2.

37. Xu H, Wang Y, Lin S, Deng W, Peng D, Cui Q, et al. PTMD: a database of human disease-associated post-translational modifications. Genomics Proteomics Bioinform. 2018;16(4):244-51.

38. Ullah S, Lin S, Xu Y, Deng W, Ma L, Zhang Y, et al. dbPAF: an integrative database of protein phosphorylation in animals and fungi. Sci Rep. 2016;6:srep23534.

39. Matlock MK, Holehouse AS, Naegle KM. ProteomeScout: a repository and analysis resource for post-translational modifications and proteins. Nucleic Acids Res. 2015;43(Database issue):D521-30.

40. Huang K-Y, Su M-G, Kao H-J, Hsieh Y-C, Jhong J-H, Cheng K-H, et al. dbPTM 2016: 10-year anniversary of a resource for post-translational modification of proteins. Nucleic Acids Res. 2016;44(D1):D435-46.

41. Cheng F, Jia P, Wang Q, Zhao Z. Quantitative network mapping of the human kinome interactome reveals new clues for rational kinase inhibitor discovery and individualized cancer therapy. Oncotarget. 2014;5(11):3697-710.

42. Huang K-Y, Wu H-Y, Chen Y-J, Lu C-T, Su M-G, Hsieh Y-C, et al. RegPhos 2.0: an updated resource to explore protein kinase-substrate phosphorylation networks in mammals. Database. 2014;2014:bau34.

43. Safaei J, Maňuch J, Gupta A, Stacho L, Pelech S. Prediction of 492 human protein kinase substrate specificities. Proteome Sci. 2011;9(Suppl 1):S6.

44. Zanzoni A, Carbajo D, Diella F, Gherardini PF, Tramontano A, HelmerCitterich M, et al. Phospho3D 2.0: an enhanced database of threedimensional structures of phosphorylation sites. Nucleic Acids Res. 2011;39(1):D268-71.

45. Davezac N, Baldin V, Blot J, Ducommun B, Tassan J-P. Human pEg3 kinase associates with and phosphorylates CDC25B phosphatase: a potential role for $\mathrm{pEg} 3$ in cell cycle regulation. Oncogene. 2002;21(50):7630-41.

46. Chauhan D, Pandey P, Hideshima T, Treon S, Raje N, Davies FE, et al. SHP2 mediates the protective effect of interleukin- 6 against dexamethasone-induced apoptosis in multiple myeloma cells. J Biol Chem. 2000;275(36):27845-50.

47. Trost B, Kusalik A. Computational prediction of eukaryotic phosphorylation sites. Bioinformatics. 2011;27(21):2927-35.

48. Miller ML, Blom N. Kinase-specific prediction of protein phosphorylation sites. Methods Mol Biol. 2009;527(299-310):X.

49. Fan W, Xu X, Shen Y, Feng H, Li A, Wang M. Prediction of protein kinasespecific phosphorylation sites in hierarchical structure using functional information and random forest. Amino Acids. 2014;46(4):1069-78.

50. Wang D, Zeng S, Xu C, Qiu W, Liang Y, Joshi T, et al. MusiteDeep: a deeplearning framework for general and kinase-specific phosphorylation site prediction. Bioinformatics. 2017;33(24):3909-16.

51. Wong $Y-H$, Lee $T-Y$, Liang H-K, Huang C-M, Wang T-Y, Yang $Y-H$, et al. KinasePhos 2.0: a web server for identifying protein kinase-specific phosphorylation sites based on sequences and coupling patterns. Nucleic Acids Res. 2007;35(1):W588-94.

52. Xue Y, Li A, Wang L, Feng H, Yao X. PPSP: prediction of PK-specific phosphorylation site with Bayesian decision theory. BMC Bioinform. 2006;20(7):163.

53. Saunders NFW, Brinkworth RI, Huber T, Kemp BE, Kobe B. Predikin and PredikinDB: a computational framework for the prediction of protein kinase peptide specificity and an associated database of phosphorylation sites. BMC Bioinform. 2008;26(9):245.

54. lakoucheva LM, Radivojac P, Brown CJ, O'Connor TR, Sikes JG, Obradovic $Z$, et al. The importance of intrinsic disorder for protein phosphorylation. Nucleic Acids Res. 2004;32(3):1037-49.
55. Durek P, Schudoma C, Weckwerth W, Selbig J, Walther D. Detection and characterization of 3D-signature phosphorylation site motifs and their contribution towards improved phosphorylation site prediction in proteins. BMC Bioinform. 2009;21(10):117.

56. Newman RH, Hu J, Rho H-S, Xie Z, Woodard C, Neiswinger J, et al. Construction of human activity-based phosphorylation networks. Mol Syst Biol. 2013;9:655

57. Song C, Ye M, Liu Z, Cheng H, Jiang X, Han G, et al. Systematic analysis of protein phosphorylation networks from phosphoproteomic data. Mol Cell Proteomics. 2012;11(10):1070-83.

58. Horn H, Schoof EM, Kim J, Robin X, Miller ML, Diella F, et al. KinomeXplorer: an integrated platform for kinome biology studies. Nat Methods. 2014;11(6):603-4.

59. Blom N, Sicheritz-Pontén T, Gupta R, Gammeltoft S, Brunak S. Prediction of post-translational glycosylation and phosphorylation of proteins from the amino acid sequence. Proteomics. 2004;4(6):1633-49.

60. LiT, Li F, Zhang X. Prediction of kinase-specific phosphorylation sites with sequence features by a log-odds ratio approach. Proteins. 2008;70(2):404-14.

61. Xue Y, Liu Z, Cao J, Ma Q, Gao X, Wang Q, et al. GPS 2.1: enhanced prediction of kinase-specific phosphorylation sites with an algorithm of motif length selection. Protein Eng Des Sel. 2011;24(3):255-60.

62. Gao J, Thelen JJ, Dunker AK, Xu D. Musite, a tool for global prediction of general and kinase-specific phosphorylation sites. Mol Cell Proteomics. 2010;9(12):2586.

63. Yang $P$, Humphrey $S J$, James DE, Yang YH, Jothi R. Positive-unlabeled ensemble learning for kinase substrate prediction from dynamic phosphoproteomics data. Bioinformatics. 2016;32(2):252-9.

64. Huang K-Y, Lee T-Y, Kao H-J, Ma C-T, Lee C-C, Lin T-H, et al. dbPTM in 2019: exploring disease association and cross-talk of post-translational modifications. Nucleic Acids Res. 2019;47(D1):D298-308.

65. Miller ML, Jensen LJ, Diella F, Jørgensen C, Tinti M, Li L, et al. Linear motif atlas for phosphorylation-dependent signaling. Sci Signal. 2008;1 (35):ra2.

66. Linding R, Jensen LJ, Ostheimer GJ, van Vugt MATM, Jørgensen C, Miron IM, et al. Systematic discovery of in vivo phosphorylation networks. Cell. 2007;129(7):1415-26.

67. Luo F, Wang M, Liu Y, Zhao X-M, Li A. DeepPhos: prediction of protein phosphorylation sites with deep learning. Bioinformatics. 2019;35:2766-73.

68. Zhao M, Zhang Z, Mai G, Luo Y, Zhou F. jEcho: an evolved weight vector to CHaracterize the protein's posttranslational modification mOtifs. Interdiscip Sci. 2015;7(2):194-9.

69. Parca L, Ariano B, Cabibbo A, Paoletti M, Tamburrini A, Palmeri A, et al. Kinome-wide identification of phosphorylation networks in eukaryotic proteomes. Bioinformatics. 2019;35(3):372-9.

70. Patrick R, Lê Cao K-A, Kobe B, Bodén M. PhosphoPICK: modelling cellular context to map kinase-substrate phosphorylation events. Bioinformatics. 2015;31(3):382-9.

71. Blom N, Gammeltoft S, Brunak S. Sequence and structure-based prediction of eukaryotic protein phosphorylation sites. J Mol Biol. 1999;294(5):1351-62.

72. Neuberger G, Schneider G, Eisenhaber F. pkaPS: prediction of protein kinase A phosphorylation sites with the simplified kinase-substrate binding model. Biol Direct. 2007;12(2):1.

73. Sing T, Sander O, Beerenwinkel N, Lengauer T. ROCR: visualizing classifier performance in R. Bioinformatics. 2005;21(20):3940-1.

74. Lachmann A, Ma'ayan A. KEA: kinase enrichment analysis. Bioinformatics. 2009;25(5):684-6.

75. Weidner C, Fischer C, Sauer S. PHOXTRACK-a tool for interpreting comprehensive datasets of post-translational modifications of proteins. Bioinformatics. 2014;30(23):3410-1.

76. Mischnik M, Sacco F, Cox J, Schneider H-C, Schäfer M, Hendlich M, et al. IKAP: a heuristic framework for inference of kinase activities from Phosphoproteomics data. Bioinformatics. 2016;32(3):424-31.

77. Beekhof R, van Alphen C, Henneman AA, Knol JC, Pham TV, Rolfs F, et al. INKA, an integrative data analysis pipeline for phosphoproteomic inference of active kinases. Mol Syst Biol. 2019;15(4):e8250.

78. Wilkes EH, Terfve C, Gribben JG, Saez-Rodriguez J, Cutillas PR. Empirical inference of circuitry and plasticity in a kinase signaling network. Proc Natl Acad Sci USA. 2015;112(25):7719-24. 
79. Subramanian A, Tamayo P, Mootha VK, Mukherjee S, Ebert BL, Gillette $M A$, et al. Gene set enrichment analysis: a knowledge-based approach for interpreting genome-wide expression profiles. Proc Natl Acad Sci. 2005;102(43):15545-50.

80. Krug K, Mertins P, Zhang B, Hornbeck P, Raju R, Ahmad R, et al. A curated resource for phosphosite-specific signature analysis. Mol Cell Proteomics. 2019;18(3):576-93.

81. Szklarczyk D, Gable AL, Lyon D, Junge A, Wyder S, Huerta-Cepas J, et al. STRING V11: protein-protein association networks with increased coverage, supporting functional discovery in genome-wide experimental datasets. Nucleic Acids Res. 2019;47(D1):D607-13.

82. Slenter DN, Kutmon M, Hanspers K, Riutta A, Windsor J, Nunes N, et al. WikiPathways: a multifaceted pathway database bridging metabolomics to other omics research. Nucleic Acids Res. 2018;46(Database issue):D661-7.

83. Petsalaki E, Helbig AO, Gopal A, Pasculescu A, Roth FP, Pawson T. SELPHI: correlation-based identification of kinase-associated networks from global phospho-proteomics data sets. Nucleic Acids Res. 2015;43(W1):W276-82.

84. Söderholm S, Hintsanen P, Öhman T, Aittokallio T, Nyman TA. PhosFox: a bioinformatics tool for peptide-level processing of LC-MS/MS-based phosphoproteomic data. Proteome Sci. 2014;12:36.

85. Terfve C, Cokelaer T, Henriques D, MacNamara A, Goncalves E, Morris MK, et al. CellNOptR: a flexible toolkit to train protein signaling networks to data using multiple logic formalisms. BMC Syst Biol. 2012;18(6):133.

86. Äijö T, Granberg K, Lähdesmäki H. Sorad: a systems biology approach to predict and modulate dynamic signaling pathway response from phosphoproteome time-course measurements. Bioinformatics. 2013;29(10):1283-91.

87. Hsu C-L, Wang J-K, Lu P-C, Huang H-C, Juan H-F. DynaPho: a web platform for inferring the dynamics of time-series phosphoproteomics. Bioinformatics. 2017;33:3664-6.

88. Yang P, Patrick E, Humphrey SJ, Ghazanfar S, James DE, Jothi R, et al. KinasePA: phosphoproteomics data annotation using hypothesis driven kinase perturbation analysis. Proteomics. 2016;16(13):1868-71.

89. Ren J, Jiang C, Gao X, Liu Z, Yuan Z, Jin C, et al. PhosSNP for systematic analysis of genetic polymorphisms that influence protein phosphorylation. Mol Cell Proteomics. 2010;9(4):623.

90. Krassowski M, Paczkowska M, Cullion K, Huang T, Dzneladze I, Ouellette $B F F$, et al. ActiveDriverDB: human disease mutations and genome variation in post-translational modification sites of proteins. Nucleic Acids Res. 2018;46(D1):D901-10.

91. Wagih O, Reimand J, Bader GD. MIMP: predicting the impact of mutations on kinase-substrate phosphorylation. Nat Methods. 2015;12(6):531-3.

92. Creixell P, Schoof EM, Simpson CD, Longden J, Miller CJ, Lou HJ, et al. Kinome-wide decoding of network-attacking mutations rewiring cancer signaling. Cell. 2015;163(1):202-17.

93. Patrick R, Kobe B, Lê Cao K-A, Bodén M. PhosphoPICK-SNP: quantifying the effect of amino acid variants on protein phosphorylation. Bioinformatics. 2017;33(12):1773-81.

94. Kim J, Yoo M, Kang J, Tan AC. K-Map: connecting kinases with therapeutics for drug repurposing and development. Hum Genomics. 2013;23(7):20

95. Goldberg JM, Griggs AD, Smith JL, Haas BJ, Wortman JR, Zeng Q. Kinannote, a computer program to identify and classify members of the eukaryotic protein kinase superfamily. Bioinformatics. 2013;29(19):2387-94.

96. McSkimming DI, Rasheed K, Kannan N. Classifying kinase conformations using a machine learning approach. BMC Bioinform. 2017;18(1):86.

97. Eid S, Turk S, Volkamer A, Rippmann F, Fulle S. KinMap: a web-based tool for interactive navigation through human kinome data. BMC Bioinform. 2017;18(1):16.

98. Douglass J, Gunaratne R, Bradford D, Saeed F, Hoffert JD, Steinbach PJ, et al. Identifying protein kinase target preferences using mass spectrometry. Am J Physiol Cell Physiol. 2012;303(7):C715-27.

99. Torii M, Li G, Li Z, Oughtred R, Diella F, Celen I, et al. RLIMS-P: an online text-mining tool for literature-based extraction of protein phosphorylation information. Database. 2014;2014:bau081. https://doi.org/10.1093/ database/bau081.
100. Arighi CN, Siu AY, Tudor CO, Nchoutmboube JA, Wu CH, Shanker VK. eFIP: a tool for mining functional impact of phosphorylation from literature. Methods Mol Biol. 2011;694:63-75.

101. Zhao B, Pisitkun T, Hoffert JD, Knepper MA, Saeed F. CPhos: a program to calculate and visualize evolutionarily conserved functional phosphorylation sites. Proteomics. 2012;12(22):3299-303.

102. Warnecke A, Sandalova T, Achour A, Harris RA. PyTMs: a useful PyMOL plugin for modeling common post-translational modifications. BMC Bioinform. 2014;28(15):370.

103. Madeira F, Tinti M, Murugesan G, Berrett E, Stafford M, Toth R, et al. 14-33-Pred: improved methods to predict 14-3-3-binding phosphopeptides. Bioinformatics. 2015;31(14):2276-83.

104. Patra KC, Wang Q, Bhaskar PT, Miller L, Wang Z, Wheaton W, et al. Hexokinase 2 is required for tumor initiation and maintenance and its systemic deletion is therapeutic in mouse models of cancer. Cancer Cell. 2013;24(2):213-28.

105. Guo Y, Peng D, Zhou J, Lin S, Wang C, Ning W, et al. EEKPD 2.0: an update with rich annotations for eukaryotic protein kinases, protein phosphatases and proteins containing phosphoprotein-binding domains. Nucleic Acids Res. 2019;47(D1):D344-50.

106. Kooistra AJ, Kanev GK, van Linden OPJ, Leurs R, de Esch IJP, de Graaf C. KLIFS: a structural kinase-ligand interaction database. Nucleic Acids Res. 2016;44(D1):D365-71.

107. Peri S, Navarro JD, Amanchy R, Kristiansen TZ, Jonnalagadda CK, Surendranath V, et al. Development of human protein reference database as an initial platform for approaching systems biology in humans. Genome Res. 2003;13(10):2363-71.

108. Mishra GR, Suresh M, Kumaran K, Kannabiran N, Suresh S, Bala P, et al. Human protein reference database—2006 update. Nucleic Acids Res. 2006;34(1):D411-4.

109. Diella F, Cameron S, Gemünd C, Linding R, Via A, Kuster B, et al. Phospho.ELM: a database of experimentally verified phosphorylation sites in eukaryotic proteins. BMC Bioinform. 2004;5:79.

110. Diella F, Gould CM, Chica C, Via A, Gibson TJ. Phospho.ELM: a database of phosphorylation sites-update 2008. Nucleic Acids Res. 2008;36(Database issue):D240-4.

111. Gnad F, Ren S, Cox J, Olsen JV, Macek B, Oroshi M, et al. PHOSIDA (phosphorylation site database): management, structural and evolutionary investigation, and prediction of phosphosites. Genome Biol. 2007;8(11):R250.

112. Tinti M, Johnson C, Toth R, Ferrier DEK, Mackintosh C. Evolution of signal multiplexing by 14-3-3-binding 2R-ohnologue protein families in the vertebrates. Open Biol. 2012;2(7):120103.

113. Lee T-Y, Bo-Kai Hsu J, Chang W-C, Huang H-D. RegPhos: a system to explore the protein kinase-substrate phosphorylation network in humans. Nucleic Acids Res. 2011;39(Database issue):D777-87.

114. Naegle KM, Welsch RE, Yaffe MB, White FM, Lauffenburger DA. MCAM: multiple clustering analysis methodology for deriving hypotheses and insights from high-throughput proteomic datasets. PLoS Comput Biol. 2011;7(7):e1002119.

115. Ovelleiro D, Carrascal M, Casas V, Abian J. LymPHOS: design of a phosphosite database of primary human T cells. Proteomics. 2009:9(14):3741-51.

116. Lee T-Y, Huang H-D, Hung J-H, Huang H-Y, Yang Y-S, Wang T-H. dbPTM: an information repository of protein post-translational modification. Nucleic Acids Res. 2006;34(Database issue):D622-7.

117. Lu C-T, Huang K-Y, Su M-G, Lee T-Y, Bretaña NA, Chang W-C, et al. DbPTM 3.0: an informative resource for investigating substrate site specificity and functional association of protein post-translational modifications. Nucleic Acids Res. 2013;41 (Database issue):D295-305.

118. Lo Surdo P, Calderone A, Cesareni G, Perfetto L. SIGNOR: a database of causal relationships between biological entities-a short guide to searching and browsing. Curr Protoc Bioinform. 2017;58:8-23.

119. Quintaje SB, Orchard S. The annotation of both human and mouse kinomes in UniProtKB/Swiss-Prot: one small step in manual annotation, one giant leap for full comprehension of genomes. Mol Cell Proteomics. 2008; $7(8): 1409$.

120. Liu Z, Ren J, Cao J, He J, Yao X, Jin C, et al. Systematic analysis of the Plk-mediated phosphoregulation in eukaryotes. Brief Bioinform. 2013;14(3):344-60. 
121. Tsaousis GN, Bagos PG, Hamodrakas SJ. HMMpTM: improving transmembrane protein topology prediction using phosphorylation and glycosylation site prediction. Biochim Biophys Acta. 2014;1844(2):316-22.

122. Zou L, Wang M, Shen Y, Liao J, Li A, Wang M. PKIS: computational identification of protein kinases for experimentally discovered protein phosphorylation sites. BMC Bioinform. 2013;13(14):247.

123. Dou Y, Yao B, Zhang C. PhosphoSVM: prediction of phosphorylation sites by integrating various protein sequence attributes with a support vector machine. Amino Acids. 2014:46(6):1459-69.

124. Wu Z, Lu M, LiT. Prediction of substrate sites for protein phosphatases 1B, SHP-1, and SHP-2 based on sequence features. Amino Acids. 2014;46(8):1919-28.

125. Obenauer JC, Cantley LC, Yaffe MB. Scansite 2.0: proteome-wide prediction of cell signaling interactions using short sequence motifs. Nucleic Acids Res. 2003;31(13):3635-41.

126. Trost B, Maleki F, Kusalik A, Napper S. DAPPLE 2: a tool for the homology-based prediction of post-translational modification sites. J Proteome Res. 2016;15(8):2760-7.

127. Qiu W-R, Xiao X, Xu Z-C, Chou K-C. iPhos-PseEn: identifying phosphorylation sites in proteins by fusing different pseudo components into an ensemble classifier. Oncotarget. 2016;7(32):51270-83.

128. Qin G-M, Li R-Y, Zhao X-M. PhosD: inferring kinase-substrate interactions based on protein domains. Bioinformatics. 2017;33(8):1197-204.

129. Wei L, Xing P, Tang J, Zou Q. PhosPred-RF: a novel sequence-based predictor for phosphorylation sites using sequential information only. IEEE Trans Nanobioscience. 2017;16(4):240-7.
130. Wang D, Liang Y, Xu D. Capsule network for protein post-translational modification site prediction. Bioinformatics. 2019;35(14):2386-94.

131. Liu Y, Wang M, Xi J, Luo F, Li A. PTM-ssMP: a web server for predicting different types of post-translational modification sites using novel sitespecific modification profile. Int J Biol Sci. 2018;14(8):946-56.

132. Li F, Li C, Marquez-Lago TT, Leier A, Akutsu T, Purcell AW, et al. Quokka: a comprehensive tool for rapid and accurate prediction of kinase familyspecific phosphorylation sites in the human proteome. Bioinformatics. 2018;34:4223-31.

133. Cao M, Chen G, Wang L, Wen P, Shi S. Computational prediction and analysis for tyrosine post-translational modifications via elastic Net. J Chem Inf Model. 2018;58(6):1272-81.

134. Ayati M, Wiredja D, Schlatzer D, Maxwell S, Li M, Koyutürk M, et al. CoPhosK: a method for comprehensive kinase substrate annotation using co-phosphorylation analysis. PLoS Comput Biol. 2019;15(2):e1006678.

\section{Publisher's Note}

Springer Nature remains neutral with regard to jurisdictional claims in published maps and institutional affiliations.
Ready to submit your research? Choose BMC and benefit from:

- fast, convenient online submission

- thorough peer review by experienced researchers in your field

- rapid publication on acceptance

- support for research data, including large and complex data types

- gold Open Access which fosters wider collaboration and increased citations

- maximum visibility for your research: over 100M website views per year

At BMC, research is always in progress.

Learn more biomedcentral.com/submissions 